\title{
Automated techniques for measuring meal size in great albatrosses
}

\author{
Junichi Sugishita $^{1 *}$, Murray McKenzie ${ }^{1}$, Leigh G. Torres ${ }^{2}$ and Philip J. Seddon ${ }^{1}$ \\ ${ }^{1}$ Department of Zoology, University of Otago, Dunedin 9016, New Zealand \\ ${ }^{2}$ Department of Fisheries and Wildlife, Marine Mammal Institute, Oregon State University, Hatfield Marine Science Center, \\ Newport, Oregon 97365, United States of America \\ *Author for correspondence (Email: jun711toroa@gmail.com)
}

Published online: 30 September 2016

\begin{abstract}
Periodic weighing of seabird chicks is labour-intensive and repeated handling can cause high levels of disturbance to chicks. Although automatic weighing systems using a fibreglass nest have been designed for albatross species with a pedestal nest made of mud, this approach is inappropriate for great albatross species (genus Diomedea) whose nests consist of a low mound of soil and vegetation. We developed an automatic weighing technique, using a digital scale beneath a natural nest, to remotely measure meal size in great albatrosses. To illustrate the system's capability when used coupled with time-lapse cameras, we present sample data by comparing meal sizes fed to chicks by male and female parents of northern royal albatross (Diomedea sanfordi). Our weighing system is not only applicable to other great albatross species, but can also be modified to allow automatic weighing of other terrestrial breeders.
\end{abstract}

Key words: albatross; automatic weighing system; meal size; nest balance; non-invasive

\section{Introduction}

Periodic weighing of seabirds, especially chicks, has been used often as a research method in studying chick provisioning of Procellariiformes seabirds (albatrosses, shearwaters and petrels) (Hamer \& Thompson 1997; Weimerskirch et al. 1997a, 1997b; Phillips \& Hamer 2000; Weimerskirch \& Lys 2000; Phillips \& Croxall 2003). However, hand-weighing is labour-intensive and the repeated handling of birds can disrupt breeding, limiting the ability to conduct detailed studies that require frequent weighing to collect a longer time series of data. One technique to acquire weight-change data with minimum disturbance to birds is the use of an automatic weighing system (e.g. Sibly \& McCleery 1980; Poole \& Jon 1982; Prince \& Walton 1984; Mulder \& Swaan 1992; Reid et al. 1999; Terauds \& Gales 2006). This method allows chicks to be weighed remotely and regularly with minimal disruption, providing information on parental nest attendance, provisioning and chick growth.

Since Prince and Walton (1984) first developed an automatic weighing system, many studies of the provisioning strategies of albatrosses have used an electronic weighing platform housed within a fibreglass artificial nest (Francis Scientific Instruments, Cambridge, UK) (Huin et al. 2000; Weimerskirch et al. 2000; Hedd et al. 2002; Pinaud \& Weimerskirch 2002; Terauds \& Gales 2006). While this is suitable for small to medium-sized albatrosses that make mud-pedestal nests, it is inappropriate for species whose nests consist of a low mound of soil and vegetation, such as the great albatrosses (genus Diomedea) (Tickell 2000; Elliott \& Walker 2013; Moore 2013; Sugishita 2013). Generally, weighing systems of the latter nest types have not been developed because the moisture content of these nest mounds changes with environmental conditions, limiting the accuracy of an above-ground automatic nest balance (c.f. Sibly \& McCleery 1980). Also, great albatross chicks become more mobile with age and can more easily move off their nests, compared to the smaller albatross species whose chicks remain on top of their pedestal nests for the duration of their nest rearing period. Furthermore, the surface of a fibreglass nest could look and feel unnatural to nesting chicks, resulting in chicks walking off the nest (R. Phillips pers. comm.). A high heat-retention capacity of fibreglass (e.g. Kumar \& Rosen 2011; Wang etal. 2013) could be problematic for long-term applications, especially at breeding colonies where heat stress due to increased temperature is a problem to breeding albatrosses, such as for northern royal albatross (Diomedea sanfordi) breeding at a small publicly viewed colony at Taiaroa Head/Pukekura, Dunedin, New Zealand (45 $46^{\prime}$ S, $\left.170^{\circ} 44^{\prime} \mathrm{E}\right)$ (Robertson 2001; Fox 2013; Chamberlain 2015).

The northern royal albatross is one of the largest Procellariiformes, endemic to New Zealand and classified as endangered according to the IUCN Red List of Threatened Species (IUCN 2014). A small fraction of the total population breeds at Taiaroa Head/Pukekura, managed by New Zealand's Department of Conservation (DOC) as a Nature Reserve (5.3 ha), while the rest of the population (over $99 \%$ of the total) breeds on the Chatham Islands. Adult birds take approximately one year to fledge a single chick and they breed biennially if successful. In addition to regular and frequent nest visits and weekly weighing of chicks to monitor their progress, a wide array of protective measures has been applied progressively to increase productivity at Taiaroa Head/Pukekura (Robertson 2001), including supplementary feeding of the chick. While frequent measuring of chick mass would provide a valuable insight into chick growth (Phillips \& Hamer 2000; Waugh et al. 2000; Weimerskirch et al. 2000; Phillips \& Croxall 2003), repeated hand-weighing of the chick to assess meal size is not an option due to inherent disturbance and the conservation sensitivities of the small colony. To date, the only available information on meal size and feeding frequency in northern royal albatross consists of the close observation of a single chick for 16 days in 1937 (Richdale 1952).

Here, we describe an automatic weighing method, based on methods used on a range of smaller albatross species (e.g. black-browed (Thalassarche melanophris), grey-headed 
(T.chrysostoma), shy (T. cauta) and light-mantled sooty (Phoebetria palpebrata) albatrosses) for the great albatross. The main aim was to develop a method that can provide quantitative insights into patterns in provisioning behaviour of northern royal albatross (as studied in other albatrosses, see table summary in Terauds and Gales (2006)). To demonstrate the utility of the system, we compared meal size delivered by male and female parents of northern royal albatross. To the best of our knowledge, this is the first automated measurement of meal size in any great albatross species.

\section{Methods}

\section{Equipment}

The automatic nest balance consisted of a heavy duty shipping scale (HD-150; My Weigh, Arizona, USA, capacity $60 \mathrm{~kg}$ ) (NZ\$140, October 2011) connected to a data logger (DT-CF02-XC and DT-MC02-XC; DATA TECNO, Kyoto, Japan) (NZ\$290, October 2011), powered by a 12V lead acid battery

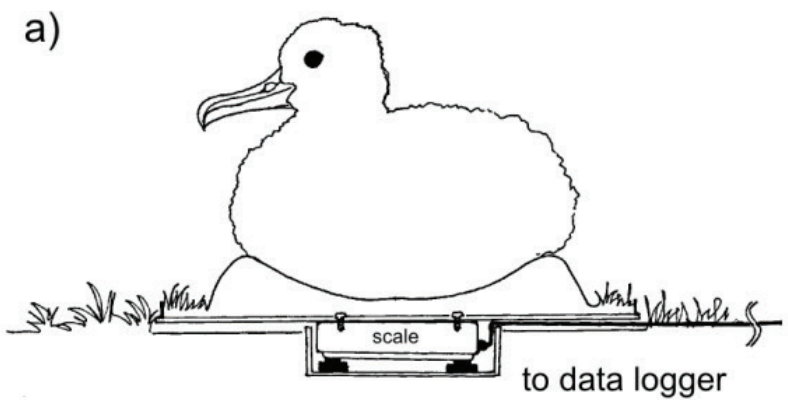

$\sim 2.5 \mathrm{~m}$ from the nest
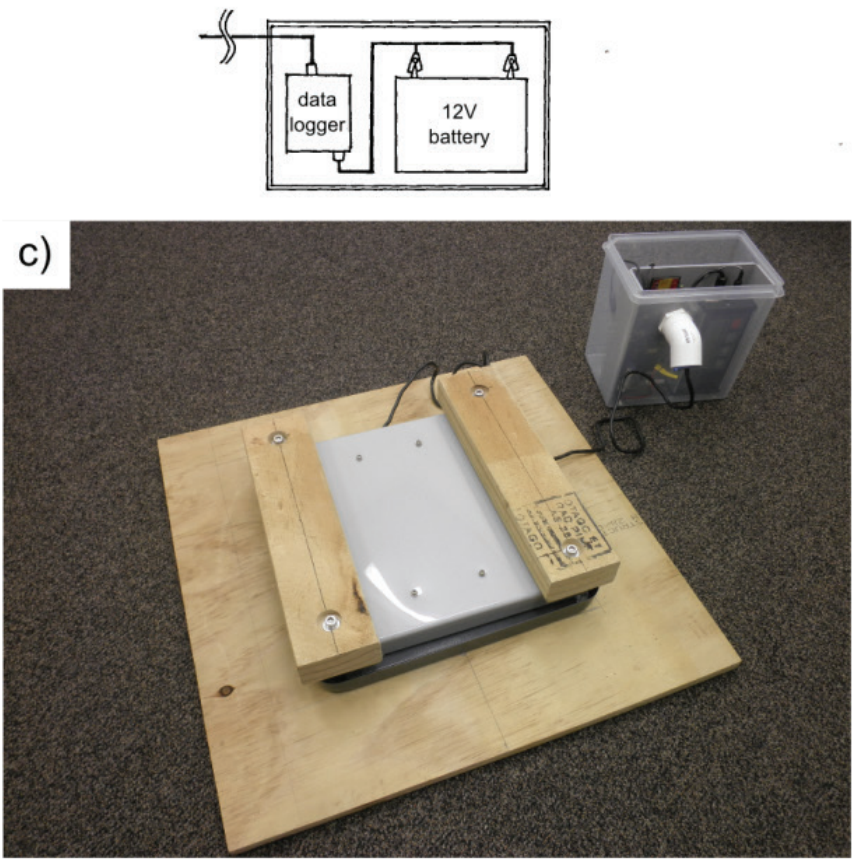

Figure 1. (a) An illustration of the automatic nest balance installed underneath a natural nest of northern royal albatross at Taiaroa Head/ Pukekura, New Zealand, (b) an image of a $12 \mathrm{~V}$ lead acid battery connected to a data-logger, both of which were housed in watertight boxes (lids are removed), placed approximately 3-4 m away from the nest, (c) an image of the underside of the scale attached to a platform of treated plywood with timber legs and (d) an image of a ceramic tile laid in a hole dug at the exact nest location, a plastic case and a natural nest placed on the scale. 
using a spirit level and a plastic case in the hole (Fig. 1d) to give the scale more stability. To further reduce wobble, the scale's mounting feet were replaced with two pieces of timber $(89 \times 38 \times 340 \mathrm{~mm})$ attached across the width of the scale (Fig. 1c). Before returning the chick to the nest, the scale was switched on and calibrated with an object of known weight. This calibration was repeated at least once per week to ensure reliability and accuracy of the measurements. We recorded the exact time when the data-logger was switched on and off so that later we could assign a timestamp for each weight reading. Each installation was completed in about 15-20 minutes. We closely monitored the nest after each installation to ensure that the chicks stayed on their nest balances and were fed by their parents.

Timing of parental feeding visits was determined remotely using time-lapse cameras (Timelapse PlantCam, Wingscapes, Inc. AL, USA) (NZ\$70, September 2011). The cameras were powered externally by a $12 \mathrm{~V}-7 \mathrm{Ah}$ sealed lead-acid battery (NZ\$30, October 2011), allowing continuous operation for at least four days. The cameras were set to continuously capture one image per minute with a timestamp from dawn to sunset using the timer function, which typically resulted in 570-630 images per day. We adjusted the timer's on/off times according to seasonal change in duration of daylight. The time-lapse cameras were placed about $1.5 \mathrm{~m}$ off the ground on a wooden broom stick with its tip capped by pipe insulation foam to avoid injury in the event of a collision. Cameras were typically deployed c. $4 \mathrm{~m}$ away from the nests so that the cameras could capture parents approaching and leaving their nests, thereby increasing a chance of identifying the unique colour band combination on the birds' legs. Images were recorded onto an SD card (4 GB) and were downloaded to a laptop computer every 3-4 days when batteries were changed. The images were reviewed to determine the time of feeding visits and identify colour bands on parent birds.

\section{Sample data}

Sample data were collected from five breeding pairs of northern royal albatross at Taiaroa Head/Pukekura during the chick-rearing period between April and July in 2013. To minimise potential adverse effects of nest manipulation on chick provisioning, we did not install nest balances until the chicks attained a mass of $4-4.5 \mathrm{~kg}$, early in the chickrearing period. We removed the nest balances a few days after chicks started to spend the majority of their time off the nest, typical behaviour after about 180 days of age. Feeding events were characterised by a steep increase in weight.
While the weight fluctuated markedly when the chick was being fed due to chick movement, once the chick was settled the weight readings stabilised, which enabled us to determine the incremental weight gain by comparing stable, constant readings before and after the feeding event. Before deployment, we tested how the weight of a nest alone changed over four days using an old nest from the previous breeding season, with a known-weight object $(3 \mathrm{~kg})$ in the nest. The test showed that a nest decreased in weight by around $1.9 \mathrm{~kg}$ over 4 days (Fig. 2). The significant weight loss was likely due to water evaporation from nesting materials (i.e. soil and vegetation) because the weather was dry and sunny during the 4-day period. This result limited our ability to measure actual chick body weight reliably.

\section{Statistical analysis}

To analyse differences in meal size delivered by male and female parents, we used linear mixed-effects models using the 'Imer' function of the 'Ime4' package (Bates et al. 2012) in R 3.1.2 statistical program (R Core Team 2014). We ran a linear mixed-effect model with meal size as a response variable and parent sex as a fixed-effect predictor variable. Individual parents were included as a random effect, nested within nest identity to account for the repeated measures of a feeding visit by the same individuals, and for the repeated measures at the same nest. All data are expressed as mean \pm 1 standard deviation, with significance level set at $\alpha=0.05$.

\section{Results}

No nests were deserted as a result of the nest manipulation and all five chicks successfully fledged from nests that had been equipped with the automatic weighing system. The body mass of the study chicks remained within the long-term average weight observed during routine hand-weighing of chicks (DOC unpubl. data). Meal sizes were calculated from weight increments immediately before and after parental feeding visits (Fig. 3), and each meal was allocated to a particular parent visiting the nest at the time as determined by time- lapse photography. Typically, data files in memory cards contained a little over 225000 or 277000 weight readings for each 3 or 4 day period, respectively.

We recorded a total of 284 meals fed to chicks by five breeding pairs. The number of meals measured for each parent bird varied from 13-49 meals ( $28 \pm 10$ meals). The duration of the nest balance operation ranged from 77-108 days

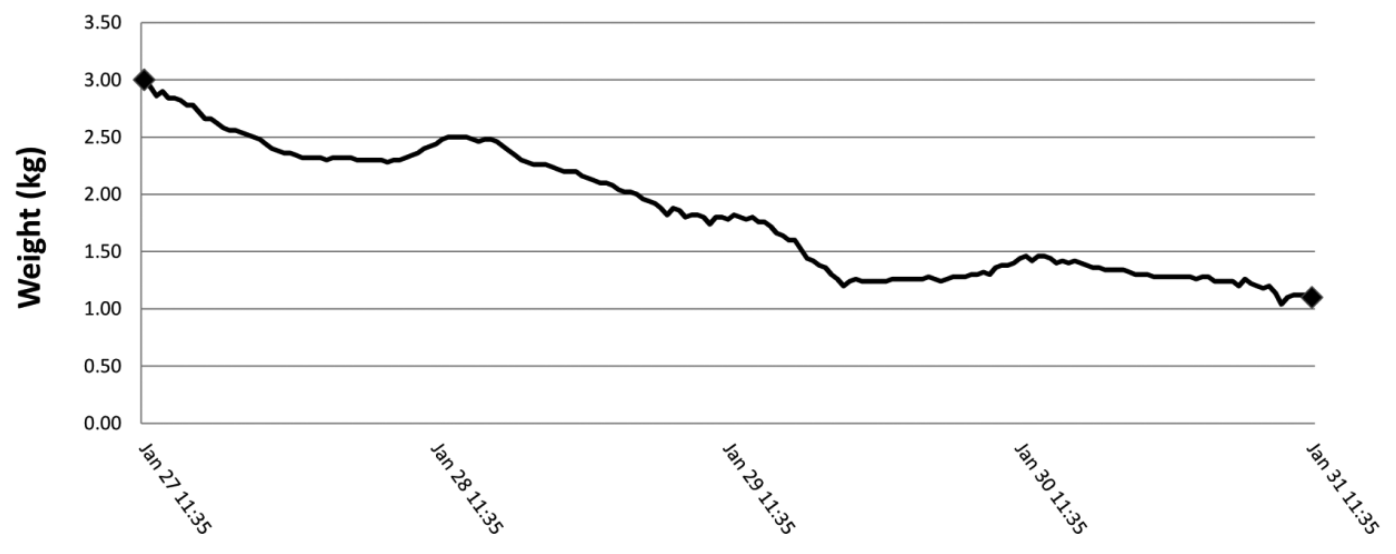

Figure 2. Changes in weight of a natural nest of northern royal albatross at Taiaroa Head/ Pukekura, New Zealand, in 4 days of dry weather. The scale was tared to zero with a nest and a known-weight object $(3 \mathrm{~kg})$ on it. 


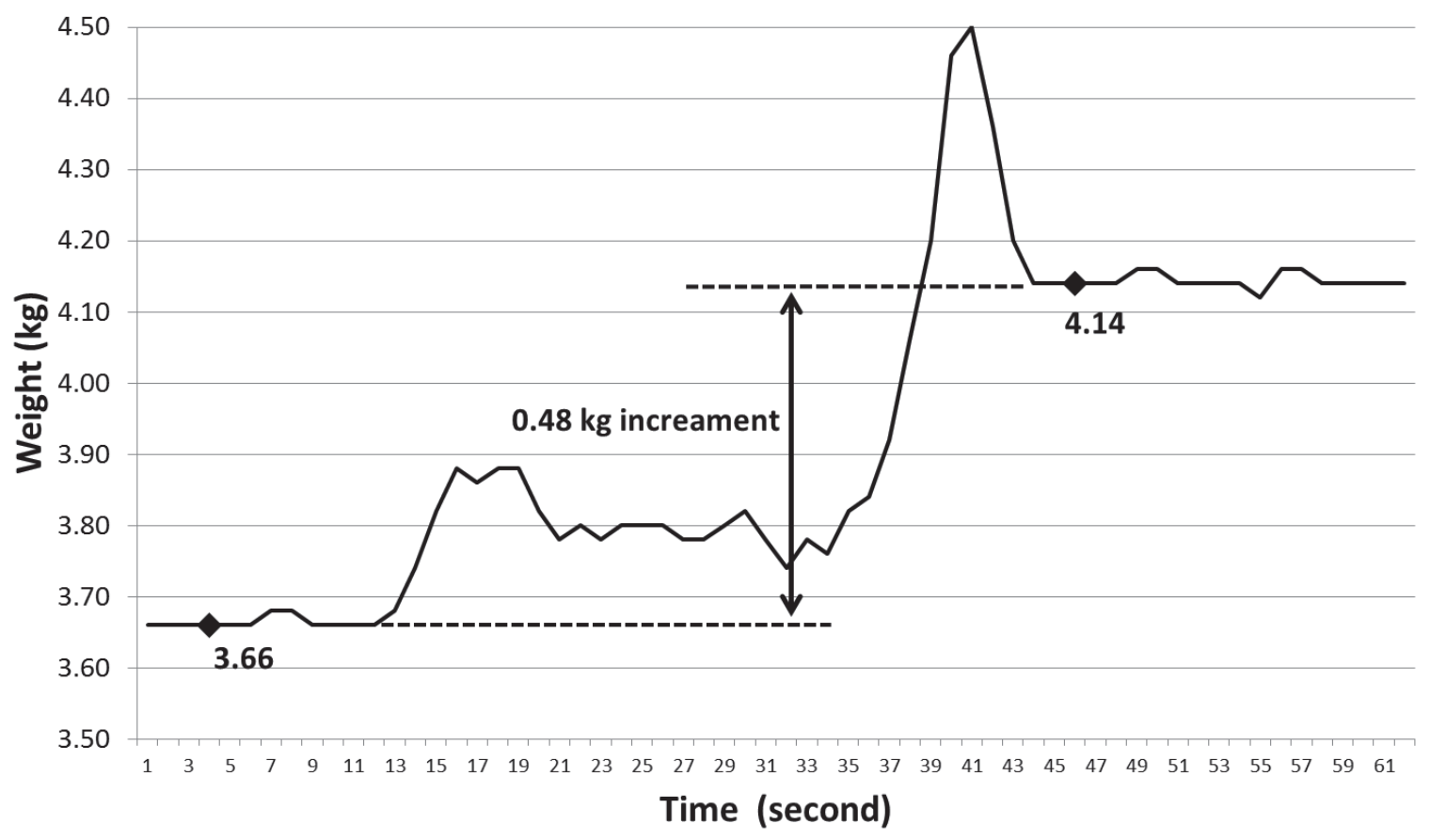

Figure 3. A typical weight increment during a parental chick feeding. Food ingestion is characterised by fluctuating weight readings (approximately between 13 and 37 seconds) bounded by relatively constant, stable weight readings. Meal sizes can be calculated as a difference between weights at periods of stable readings before and after a feeding event. A big spike after feeding (at about between 39 and 45 seconds) occurs typically as a result of the chick getting up and shaking its body before sitting down. The weight shown is not necessarily the weight of a chick due to weight variability of a natural nest.

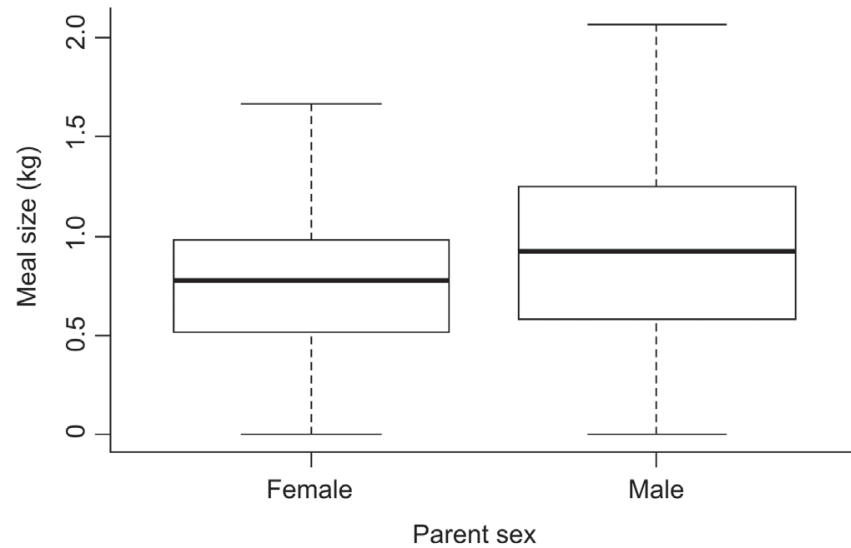

Figure 4. Boxplot of mean meal size fed by male and by female parent northern royal albatrosses at Taiaroa Head/Pukekura, New Zealand.

(94 \pm 11 days). Several feeding visits were removed from the data analysis because we could not allocate the event unequivocally to a particular parent as the colour bands were obscured by grass or light conditions. In both sexes, meal size showed a considerable range and varied from $0-2.06$ $\mathrm{kg}$ and $0-1.66 \mathrm{~kg}$ for male and female, respectively. On five occasions, chicks received no meals during a parent's nest visit. Mean meal size was about 20\% larger for male parents than for female parents, but not statistically different (male: $0.92 \pm 0.45 \mathrm{~kg}$ and female: $0.77 \pm 0.34 \mathrm{~kg}$ ) (mixed model: effect of parent sex, $F 1,3.9=4.1, P=0.1142$ ) (Fig. 4).

Additionally, the weight of six parent birds was opportunistically recorded by our nest balances when parents
Table 1. The body weight of adult northern royal albatrosses at Taiaroa Head/Pukekura, New Zealand, during the chick-rearing period. The measurements were taken opportunistically using the automatic nest balances.

\begin{tabular}{lll}
\hline No. & Sex & Weight $(\mathrm{kg})$ \\
\hline 1 & Male & 9.60 \\
2 & Male & 8.74 \\
3 & Female & 7.18 \\
4 & Female & 6.88 \\
5 & Female & 7.20 \\
6 & Female & 7.93 \\
\hline
\end{tabular}

voluntarily stepped on and off the nest balances when their chicks were outside their nests (Table 1). Because of the brevity of each of these events (within a minute) and our short sampling interval, the weight variability of natural nests was not a factor in determining the weight of the adult birds.

\section{Discussion}

The automatic weighing system developed in this study was relatively easy and quick to deploy, and both chicks and parents appeared to adjust rapidly to the change at their nests. The system proved to be sturdy in a harsh coastal environment 
and enabled the measurement of meal size of northern royal albatross over a 3 month period without needing to directly handle the chicks. After 3 months, the weighing system did not show any sign of rust. Because parent birds feed their chicks by regurgitation while standing next to the nests, the weight of the parents did not interfere with calculation of meal sizes. As proven in other avian studies (e.g. Weller \& Derksen 1972; Cutler \& Swann 1999; Reif \& Tornberg 2006), time-lapse photography was effective in determining the time of feeding events and to allocate meals to specific parents. The combined use of our nest balance and timelapse cameras is relatively inexpensive; the total cost per nest was about NZ\$670 (US\$435) (excluding costs for shipping and other minor components). In comparison, in 2010 the cost for making an equivalent weighing platform with a fibreglass artificial nest was estimated at NZ\$2605-\$3260 (US\$1685-\$2108) (Francis Scientific Instruments, Cambridge, UK, pers. comm.).

The quantitative evaluation of our sample data proves that our technique is capable of obtaining results similar to those collected for smaller albatrosses that use the system produced by Francis Scientific Instruments (Huin et al. 2000; Weimerskirch et al. 2000; Hedd et al. 2002; Pinaud \& Weimerskirch 2002; Terauds \& Gales 2006). Using our technique, we demonstrated that meal sizes fed to chicks varied greatly from one feeding to the next. Some parental visits resulted in no food being delivered to chicks. Although our sample data indicate that male parents provide $20 \%$ larger meals (by mass) than females, this result will need to be substantiated with further data. For the sake of demonstrating the capability of our system, we only compared meal size. In future studies, this type of data collection system could be used to evaluate how meal size may vary with individual quality of the parent and among years with varying resource availability. With the same equipment setup, it is easy to obtain information on foraging trip duration and fasting interval, both of which are important parameters in studies of chick provisioning (e.g. Weimerskirch et al. 1993; Waugh et al. 2000; Phillips \& Croxall 2003; Phillips et al. 2009). Our weighing system not only provides a means for obtaining quantitative insights into provisioning patterns of great albatrosses, but also offers a valuable approach to studies of seabird ecology. It is possible to investigate the ecological ramifications of seabird-fishery overlap by linking foraging success (i.e. meal size) and foraging overlap with fisheries (Sugishita et al. 2015). Similarly, the inclusion of the quantity of food delivered to offspring in foraging studies provides an avenue for evaluating habitat quality to detect individual and species response to broader climate changes.

Successful measurement of meal size was largely dependent on the propensity of the chick to stay on the nest. Individual chicks appear to vary in their behaviour, with some chicks spending more time off the nests than others and some getting off the nests for feeding then back onto the nest. The same patterns were observed in chicks at un-manipulated nests in the colony. Due to this behaviour, we were unable to measure meal size after the chicks reached around 180 days of age. This timing coincides with the time when northern royal albatross chicks normally attain their peak body weight (DOC unpubl. data). Furthermore, our use of natural nests precluded the ability to measure chick body weight because the weight of nests naturally changes over time. Both the nest balances and the time-lapse cameras require external batteries for continuous use, necessitating battery changes every 4 days. This power supply limits the application of our method in areas where regular battery charging is difficult. To overcome this shortcoming, solarpanels for powering the system and/or charging batteries could be considered, although for logistical reasons this was not an option for us. Such an autonomous system could reduce the number of visits to the nest site and hence the disturbance although the system still should be calibrated and checked for errors regularly. The use of remote-downloading through wireless technologies such as Bluetooth ${ }^{\circledR}$ could be considered if sufficient funding were available.

Lastly, we believe that the adult body mass data, opportunistically recorded during this study, is valuable because the available information on adult weight of this species is limited (Murphy 1936) (6350-6804 g; sample size not given). Another possible application of our weighing system might be in conjunction with a feeding station to monitor body condition of large ground dwelling bird species, particularly of threatened species in captive breeding and reintroduction programmes (Seddon et al. 2007).

In this study, we described an automatic nest balance system, utilising a commercially available digital scale, that allows data collection of meal size for great albatrosses without repeatedly handling their chicks. Although use of natural nests impeded the measurement of actual chick body weight, we demonstrated that our nest balances could be an effective tool in provisioning studies, especially when used together with the time-lapse photography. We believe our system could be modified to allow automatic weighing of other terrestrial breeders.

\section{Acknowledgements}

JS received funding for this study from: the Department of Zoology, University of Otago; and jointly the Otago Peninsula Trust and DepartmentofConservation Otago Conservancy. We gratefully acknowledge L. Perriman for his advice and help in the field and for sharing unpublished data. We are indebted to the Korako Karetai Trust and Otakou Runanga for consents to carry out the field work in a culturally significant site and to Port Otago Limited for allowing us to use their facility at Taiaroa Head as a battery charging station. We are grateful to D. Ochi for lending data loggers used with the nest balances and to E. King for his help on building a prototype nest balance. We also thank M. Francis, R. Phillips, R. Gales and G. Elliot for invaluable information on weighing systems, and $\mathrm{S}$. Briden for her help in the field, as well as D. Agnew and B. McKinlay for discussion on the nest balance. We would like to thank the two referees, P. Moore and P. Scofield, for their valuable comments and corrections on the first version of the manuscript. This study was authorized by the University of Otago Animal Ethics Committee (AEC 71/11) and by New Zealand's Department of Conservation (OT-32054-RES).

\section{References}

Bates D, Maechler M, Bolker B 2012. lme4: linear mixedeffects models using S4 classes. R package version 0.999375-42. CRAN.R-project.org/package=lme4.

Chamberlain R 2015. Heat goes on but nesting albatrosses unharmed. Otago Daily Times, www.odt.co.nz/news/ dunedin/367805/heat-goes-nesting-albatrosses-unharmed (accessed by 23 December 2015). 
Cutler TL, Swann DE 1999. Using remote photography in wildlife ecology: a review. Wildlife Society Bulletin 27: 571-581.

Elliott GP, Walker KJ 2013. Antipodean albatross. In: Miskelly $\mathrm{CM}$ ed. New Zealand birds online. www.nzbirdsonline. org.nz.

Fox R 2013. Albatross dies as heat stress affects colony. Otago Daily Times. www.odt.co.nz/news/dunedin/244323/ albatross-dies-heat-stress-affects-colony (accessed 23 December 2015).

Hamer KC, Thompson DR 1997. Provisioning and growth rates of nestling Fulmars Fulmarus glacialis: stochastic variation or regulation? Ibis 139: 31-39.

Hedd A, Gales R, Brothers N 2002. Provisioning and growth rates of shy albatrosses at Albatross Island, Tasmania. The Condor 104: 12-29.

Huin N, Prince PA, Briggs DR 2000. Chick provisioning rates and growth in Blacklbrowed Albatross Diomedea melanophris and Grey-headed Albatross D. chrysostoma at Bird Island, South Georgia. Ibis 142: 550-565.

IUCN 2014. IUCN Red List of Threatened Species.

Kumar R, Rosen MA 2011. Integrated collector-storage solar water heater with extended storage unit. Applied Thermal Engineering 31: 348-354.

Moore PJ 2013. Southern royal albatross. In: Miskelly CM ed. New Zealand birdsonline. www.nzbirdsonline.org.nz.

Mulder J, Swaan A 1992. Body-weight changes of egg-laying curlews Numenius arquata, as monitored by an automatic weighing system. Ardea 80: 273-279.

Murphy RC 1936. Oceanic Birds of South America, Vol. 1. New York, The American Museum of Natural History. 640 p.

Phillips RA, Croxall JP 2003. Control of provisioning in grey-headed albatrosses (Thalassacrche chrysostoma): do adults respond to chick condition? Canadian Journal of Zoology 81: 111-116.

Phillips RA, Hamer KC 2000. Periodic weighing and the assessment of meal massand feeding frequency in seabirds. Journal of Avian Biology 31: 75-80.

Phillips R, Wakefield E, Croxall J, Fukuda A, Higuchi H 2009. Albatross foraging behaviour: no evidence for dual foraging, and limited support for anticipatory regulation of provisioning at South Georgia. Marine Ecology Progress Series 391: 279-292.

Pinaud D, Weimerskirch H 2002. Ultimate and proximate factors affecting the breeding performance of a marine top-predator. Oikos 99: 141-150.

Poole A, Jon S 1982. A scale for weighing birds at habitual perches. Journal of Field Ornithology 53: 409-414.

Prince PA, Walton DWH 1984. Automated measurement of meal sizes and feeding frequency in albatrosses. Journal of Applied Ecology 21: 789-794.

R Core Team 2014. R: a language and environment for statistical computing. Version 3.0.3. Vienna, Austria: R Foundation for Statistical Computing. www.R-project.org.

Reid K, Gordon ML, Prince PA, Croxall JP 1999. Measurement of chick provisioning in Antarctic Prions Pachyptila desolata using an automated weighing system. Journal of Avian Biology 30: 127-134.
Reif V, Tornberg R 2006. Using time-lapse digital video recording for a nesting study of birds of prey. European Journal of Wildlife Research 52: 251-258.

Richdale LE 1952. Post-egg period in albatrosses. Biological Monographs 4: 1-166.

Robertson CJR 2001. Effects of intervention on the royal albatross population at Taiaroa Head, Otago, 1937-2001. DOC Science Internal Series 23. Wellington, NewZealand, Department of Conservation. $13 \mathrm{p}$.

Seddon PJ, Armstrong DP, Maloney RF 2007. Developing the science of reintroduction biology. Conservation Biology 21: 303-312.

Sibly RM, McCleery RH 1980. Abalance for weighing groundnesting birds. Journal of Applied Ecology 17: 323-327.

Sugishita J 2013. Northern royal albatross. In: Miskelly CM ed. New Zealand birds online.

Sugishita J, Torres LG, Seddon PJ 2015. A new approach to study of seabird-fishery overlap: connecting chick feeding with parental foraging and overlap with fishing vessels. Global Ecology and Conservation 4: 632-644.

Terauds A, Gales R 2006. Provisioning strategies and growth patterns of light-mantled sooty albatrosses Phoebetria palpebrata on Macquarie Island. Polar Biology 29: 917-926.

Tickell WLN 2000. Albatrosses. New Haven, Yale University Press. 488 p.

Wang P, Yokoo K, Wakiya Y, Tanaka M 2013. Thermal balance analysis of activated-sludge process for pig slurry treatment. Biosystems Engineering 116: 368-378.

Waugh SM, Weimerskirch H, Cherel Y, Prince PA 2000. Contrasting strategies of provisioning and chick growth in two sympatrically breeding albatrosses at Campbell Island, New Zealand. The Condor 102: 804-813.

Weimerskirch H, Lys P 2000. Seasonal changes in the provisioning behaviour and mass of male and female wandering albatrosses in relation to the growth of their chick. Polar Biology 23: 733-744.

Weimerskirch H, Salamolard M, Sarrazin F, Jouventin P 1993. Foraging strategy of wandering albatrosses through the breeding season: a study using satellite telemetry. The Auk 110: 325-342.

Weimerskirch H, Cherel Y, Cuenot-ChailletF, Ridoux V 1997a. Alternative foraging strategies and resource allocation by male and female wandering albatrosses. Ecology 78: 2051-2063.

Weimerskirch H, Mougey T, Hindermeyer X 1997b. Foraging and provisioning strategies of black-browed albatrosses in relation to the requirements of the chick: natural variation and experimental study. Behavioral Ecology 8: 635-643.

Weimerskirch H, Prince PA, Zimmermann L 2000. Chick provisioning by the yellow-nosed albatross Diomedea chlororhynchos: response of foraging effort to experimentally increased costs and demands. Ibis 142: 103-110.

Weller MW, Derksen DV 1972. Use of time-lapse photography to study nesting activities of birds. The Auk 89: 196-200. 